\title{
Understanding child disadvantage from a social determinants perspective
}

\author{
Sharon Goldfeld, ${ }^{1,2}$ Meredith O'Connor, ${ }^{1,2}$ Dan Cloney, ${ }^{1,3}$ Sarah Gray, ${ }^{1}$ \\ Gerry Redmond, ${ }^{4}$ Hannah Badland, ${ }^{5}$ Katrina Williams, ${ }^{2,6,7}$ Fiona Mensah, 2,8 \\ Sue Woolfenden, ${ }^{1,9,10}$ Amanda Kvalsvig, ${ }^{1}$ Anita T Kochanoff ${ }^{11}$
}

\begin{abstract}
- Additional material is published online only. To view please visit the journal online (http://dx.doi.org/10.1136/ jech-2017-209036).
\end{abstract}

For numbered affiliations see end of article.

\section{Correspondence to}

Prof Sharon Goldfeld, Centre for Community Child Health, Royal Children's Hospital, Parkville, Victoria 3052, Australia; sharon. goldfeld@rch.org.au

Received 3 February 2017 Revised 8 November 2017 Accepted 30 November 2017 Published Online First 20 December 2017
Check for updates

To cite: Goldfeld S,

O'Connor M, Cloney D, et al. J Epidemiol Community Health 2018;72:223-229.

\begin{abstract}
Background Child health and developmental inequities exist in all countries. Comprehensive and robust concepts of disadvantage are fundamental to growing an evidence base that can reveal the extent of inequities in childhood, and identify modifiable leverage points for change. We conceptualise and test a multidimensional framework of child disadvantage aligned to a social determinants and bioecological perspective.
\end{abstract}

Methods The Longitudinal Study of Australian Children is a nationally representative sample of two cohorts of Australian children, including the birth cohort of 5107 infants, which commenced in May 2004. The analysis focused on disadvantage indicators collected at age 4-5 years. Confirmatory factor analysis was used to test a theoretically informed model of disadvantage. Concurrent validity was examined through associations with academic performance at 8-9 years.

Results The model comprising four latent factors of sociodemographic (10 indicators), geographical environments (three indicators), health conditions (three indicators) and risk factors (14 indicators) was found to provide a better fit for the data than alternative models. Each factor was associated with academic performance, providing evidence of concurrent validity.

Conclusion The study provides a theoretically informed and empirically tested framework for operationalising relative child disadvantage. Understanding and addressing inequities will be facilitated by capturing the complexity of children's experiences of disadvantage across the multiple environments in which their development unfolds.

\section{INTRODUCTION}

Disadvantage is multifaceted. Philosophical perspectives emphasise disadvantage as limiting opportunity and the capacity for individuals to freely lead lives they have reason to value. ${ }^{1}$ In the context of health equity, disadvantage refers to relative position in a social hierarchy determined by wealth, power and prestige. ${ }^{2}$ In contrast to concepts of poverty that focus on those who are the most deprived (eg, of money or material possession), socially excluded and/or vulnerable, ${ }^{3}$ disadvantage exists on a continuum.

For children, disadvantage manifests as the circumstances in which they live, learn and develop that drive differential health and developmental outcomes. $^{4}$ Children experience poorer health and developmental outcomes with successively higher levels of disadvantage, evidencing the significance of relative position on the disadvantage continuum. ${ }^{5-10}$ These differential outcomes represent inequities that are unjust, unnecessary and preventable, and due to population differences in social, demographic or economic circumstances. ${ }^{4} 11$ Inequities exist in all countries, including Australia, across children's physical health, social-emotional well-being and learning. ${ }^{4} 12$

Exposure to early disadvantage and inequity constitutes a significant and ongoing public health problem with major implications for public policy. The capacity to change developmental trajectories declines with age; therefore, failure to redress early inequities results in increasingly wide disparity gaps in rates of mortality and physical, social and cognitive impairments in adulthood. ${ }^{13}$ The WHO Commission on Social Determinants of Health has called for the elimination of inequitable health outcomes within a generation. ${ }^{4}{ }^{14}$ Developing policy to achieve the goal of 'equity from the start' depends on a rigorous understanding of the extent of the problem and identification of the modifiable leverage points for change. ${ }^{15}$ The robust conceptualisation and measurement of disadvantage in the child population is fundamental to growing this evidence base.

In operationalising the concept of disadvantage, conventional approaches typically measure children's experiences of disadvantage as socioeconomic status (eg, parental education, occupation and income), but this is inadequate in failing to capture the complex and multifaceted ways in which disadvantage can manifest. The literature on poverty suggests that material and socioeconomic factors alone substantially underestimate the extent of poverty experienced by children in a given population. ${ }^{3}{ }^{16-18}$ In relation to disadvantage, such approaches cannot reveal the full extent of social gradients in children's health and developmental outcomes, and are unable to capture the pathways through which disadvantage shapes children's access to opportunities. This may limit the identification of specific strategies to reduce existing child health and developmental inequities that can helpfully inform policy. ${ }^{19}$

To address these issues, we propose a social determinants approach that also considers the bioecological settings in which child development occurs as a paradigm for understanding and operationalising disadvantage (figure 1). The bioecological perspective suggests that children's biology interacts with 


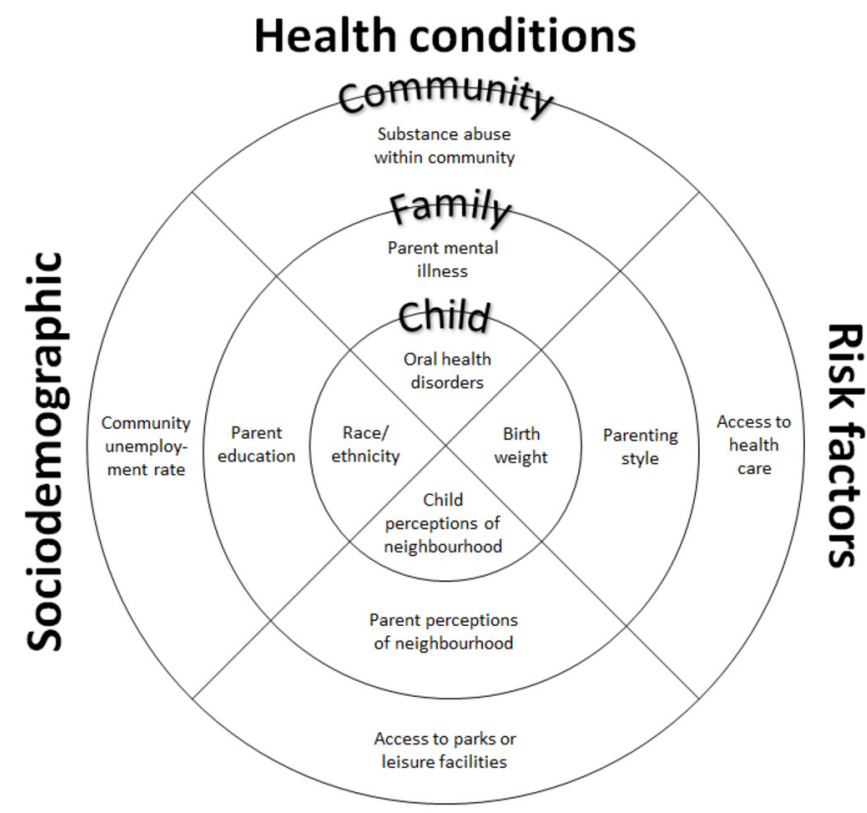

Geographic environments

\section{Time}

Figure 1 Proposed framework of child disadvantage aligning a social determinants ${ }^{22}$ and bioecological ${ }^{20}$ perspective. Examples of relevant indicators within each lens (sociodemographic, geographical environments, health conditions and risk factors) and level (child, family and community) are shown. It is expected that disadvantage experienced through each of these lenses will overlap and interact to influence inequities in complex ways. ${ }^{22}$

the multiple nested levels of their surrounding social and physical environments to shape child development. ${ }^{20}$ Sources of disadvantage may therefore arise at the individual level (eg, poor nutrition), family level (eg, low parent education) and community level (eg, dangerous neighbourhood). ${ }^{21}$

A social determinants perspective sits comfortably with this developmental paradigm. Social determinants refer to the 'conditions in which people are born, grow, live, work, and age'. ${ }^{4}$ Koh et $a l^{22}$ proposed that social determinants can be viewed through four overlapping 'lenses' or perspectives. The sociodemographic lens captures characteristics (eg, ethnicity) that define subpopulation groups that are at risk of poorer outcomes by virtue of their membership in that group. The geographical environments lens captures the characteristics of the places in which children live that drive inequities through processes such as socioeconomic segregation and barriers to services. The health conditions lens captures diagnosable conditions that drive inequities due to being unevenly distributed across social groups. The risk factors lens captures attributes, characteristics and exposures that increase the likelihood of poor child health and developmental outcomes, and are again unevenly distributed across the population. It is expected that disadvantage experienced through each of these lenses will overlap and interact to influence inequities in complex ways, ${ }^{22}$ and each of these lenses will manifest across children's ecological settings.

In this study, we empirically test the proposed framework (figure 1) of relative child disadvantage aligned with both bioecological $^{20}$ and social determinants ${ }^{22}$ perspectives. Disadvantage is measured at 4-5 years as children approach a key transition with the start of formal schooling. ${ }^{23}$ We compare different ways of structuring the data to identify an optimal model. We then examine concurrent validity of the factors derived from this model through associations with academic performance because an established research base suggests that a sound assessment of disadvantage should correlate with this outcome. ${ }^{12}$ The aim is to obtain a well-tested child-specific framework for understanding and operationalising disadvantage, which can be used to more accurately quantify the extent of child inequities and reveal policy-sensitive intervention pathways.

\section{METHOD}

\section{Data source}

Growing Up in Australia: the Longitudinal Study of Australian Children (LSAC) is a nationally representative sample of two cohorts of Australian children-the birth cohort (B-cohort) of 5107 infants on which the current study is focused and the kindergarten cohort (K-cohort) of 4983 children aged 4 yearseach of which commenced in May 2004. ${ }^{24}$ The LSAC design and sampling methodology is documented elsewhere. ${ }^{24} 25$ In short, a complex survey design was used to select a sample that was broadly representative of all Australian children except those living in remote areas. ${ }^{25}$ Data are collected on multiple aspects of child development as well as family and community characteristics, and multiple information sources are used, including parent interview, direct child assessments and observational measures, parent and teacher self-report questionnaires, and linkage to administrative datasets.

The current paper draws on data from the B-cohort $(51.2 \%$ male), focusing on primarily parent-reported data collected at wave 3 when children were aged 4-5 years (school entry). At wave 3, the B-cohort consisted of 4386 children, representing $85.9 \%$ of the original sample; this level of attrition compares well with similar cohort studies (eg, ref 26). Missing data within wave 3 were low (average of $5.71 \%$ missing in the variables used). To examine concurrent validity, we also drew on children's results from a direct assessment of academic skills at 8-9 years: the National Assessment Program-Literacy and Numeracy (NAPLAN) conducted on all Australian students. NAPLAN was successfully linked for $n=3790(86.4 \%)$ of the wave 3 participants. $^{27}$

\section{Measures \\ Disadvantage indicators at $4-5$ years}

To operationalise the disadvantage framework illustrated in figure 1 , indicators signalling disadvantage across the bioecological levels (individual, family, community) and social determinant lenses (sociodemographic, geographical environments, health conditions and risk factors) were selected if they were (1) available in the LSAC dataset, (2) relevant at the focal time point of 4-5 years and (3) identified in the literature as salient to child developmental outcomes (see online supplementary file for details).

The rich data available in LSAC allowed all four lenses across bioecological settings to be operationalised with some exceptions, mostly at the community level. Where multiple LSAC variables were available to measure the same construct, selection was based on measurement qualities (ie, validity, reliability) and best practice measurement of that construct. Variables contained a mixture of dichotomous and continuous indicators; the full range of scores available for continuous indicators was retained to capture variation across their continuum (eg, from optimal parenting to less effective parenting behaviours). 
Because the social determinant lenses overlap, some variables could be aligned with more than one lens. For example, children with a disability were considered a population of children with special needs therefore aligning with the sociodemographic lens, but their disability could alternatively have been qualified in the health conditions lens. Caregiver disability, on the other hand, fits more conventionally in the health conditions lens, rather than considering children to be part of a population who have a parent with a disability. In ambiguous cases, indicators were categorised based on what most closely resembled the original theoretical model presented by Koh et al. ${ }^{22}$

Table 1 provides a summary of the disadvantage indicators analysed at $4-5$ years (see refs ${ }^{28} 29$ for further details). Note that indicators were not available for some cells of table 1 due to a lack of suitable measures in the dataset (eg, risk factors at the community level).

\section{Academic performance at 8-9 years}

NAPLAN $^{27}$ is an Australia-wide direct assessment of academic skills conducted in schools with all children in grades $3,5,7$ and 9. NAPLAN measures students' skills in reading, writing, spelling, grammar and punctuation, and numeracy, which are mapped onto achievement scales with scores that range from 0 to 1000 . Given that the subscales are highly correlated $(r=0.69$ to $r=0.84)$, the mean across these subscales was taken for each child as an indicator of general academic performance at $8-9$ years.

\section{Analytic approach}

Analyses were conducted using Mplus V.7.3. All models were analysed with simultaneous multiple imputation to account for missing data, with five datasets created and pooled estimates reported.

First, we empirically tested the proposed framework of childhood disadvantage as operationalised within LSAC (table 1). Four different ways of structuring the data could be hypothesised from the theoretical framework:

1. A single, global disadvantage factor.

2. A three-factor model representing the bioecological levels of child, family and community.

3. A four-factor model representing the social determinant lenses of sociodemographic, geographical environments, health conditions and risk factors.

4. A twelve-factor model representing the four social determinant lenses interacting with the bioecological levels.

We used confirmatory factor analysis (CFA) to compare these different ways of structuring the data. CFA allows the extent to which a theorised underlying covariance structure fits the observed data to be explicitly tested, and for the fit of different theorised models (comprising different numbers of latent factors) to be statistically compared. Latent factors are not directly measured but are inferred from multiple observed variables that reflect variation in the same underlying construct. The four theorised models were compared according to absolute fit using Bayesian posterior predictive checking (PPC). ${ }^{30}$ The optimal model was determined to be that with the PPC estimate closest to zero (ie, the least deviance from data simulated from the theoretical covariance structure) that also did not overlap with the credibility interval of a more parsimonious model. CFA was performed over exploratory factor analysis because CFA is preferred when there is a strong theory underlying the structure of the measurement model, as was the case here. $^{31}$
Table 1 Disadvantage indicators measured in LSAC at 4-5 years according to the four social determinant lenses and bioecological setting

\begin{tabular}{llll}
\hline & Child & Family & Community \\
\hline Sociodemographic & $\begin{array}{l}\text { Child speaks } \\
\text { language other } \\
\text { than English }\end{array}$ & Main caregiver speaks & language other than \\
& $\begin{array}{l}\text { Child has } \\
\text { medical }\end{array}$ & Main caregiver income \\
& & \\
& condition or \\
disability &
\end{tabular}

Household income

Main caregiver level of

education

Main caregiver occupation

Main caregiver

financial hardship

Parents of child are partners

Number of people in

household

\begin{tabular}{|c|c|c|c|}
\hline \multirow[t]{2}{*}{$\begin{array}{l}\text { Geographical } \\
\text { environments }\end{array}$} & & $\begin{array}{l}\text { Neighbourhood } \\
\text { liveability }\end{array}$ & $\begin{array}{l}\text { Urban versus } \\
\text { regional location } \\
\text { (L) }\end{array}$ \\
\hline & & & $\begin{array}{l}\text { Community } \\
\text { socioeconomic } \\
\text { status (L) }\end{array}$ \\
\hline \multirow[t]{2}{*}{ Health conditions } & $\begin{array}{l}\text { Child tooth } \\
\text { decay }\end{array}$ & $\begin{array}{l}\text { Main caregiver } \\
\text { depression }\end{array}$ & \\
\hline & & $\begin{array}{l}\text { Main caregiver medical } \\
\text { condition or disability }\end{array}$ & \\
\hline \multirow[t]{10}{*}{ Risk factors } & $\begin{array}{l}\text { Child body mass } \\
\text { index (D) }\end{array}$ & $\begin{array}{l}\text { Main caregiver body } \\
\text { mass index }\end{array}$ & \\
\hline & $\begin{array}{l}\text { Child eats high } \\
\text { fat foods and } \\
\text { high sugar } \\
\text { drinks }\end{array}$ & $\begin{array}{l}\text { Main caregiver smoking } \\
\text { status }\end{array}$ & \\
\hline & $\begin{array}{l}\text { Child unmet } \\
\text { need for services }\end{array}$ & $\begin{array}{l}\text { Main caregiver binge } \\
\text { drinking }\end{array}$ & \\
\hline & $\begin{array}{l}\text { Child physical } \\
\text { inactivity }\end{array}$ & $\begin{array}{l}\text { Main caregiver physical } \\
\text { arguments with partner }\end{array}$ & \\
\hline & & $\begin{array}{l}\text { Home education } \\
\text { environment }\end{array}$ & \\
\hline & & $\begin{array}{l}\text { Number of homes child } \\
\text { lived in }\end{array}$ & \\
\hline & & $\begin{array}{l}\text { Main caregiver } \\
\text { argumentative partner } \\
\text { relationship }\end{array}$ & \\
\hline & & $\begin{array}{l}\text { Main caregiver angry } \\
\text { parenting style }\end{array}$ & \\
\hline & & $\begin{array}{l}\text { Stressful life events } \\
\text { within the family }\end{array}$ & \\
\hline & & $\begin{array}{l}\text { Main caregiver unmet } \\
\text { need for social support }\end{array}$ & \\
\hline
\end{tabular}

All variables are parent reported except where indicated.

D, direct assessment; L, linked data; LSAC, Longitudinal Study of Australian Children.

After identifying the optimal model, continuous scores for each latent factor were generated for each participant, with five plausible values (PVs) imputed. PVs provide an estimate of the plausible range of children's scores on the unobserved latent factors. ${ }^{32}$ Five imputed PVs were considered sufficient as no 
Table 2 Model fit according to posterior predictive checking (PPC)

Posterior predictive checking $(95 \% \mathrm{Cl})$

\section{Model}

Single, global factor

Three-factor bioecological model

4658.39 to 5031.41

Four-factor lenses model

4192.33 to 4577.92

Twelve-factor bioecological by lenses model

2979.81 to 3318.19

3135.27 to 3480.68

information gain was expected beyond this. ${ }^{33}$ Scale reliability was assessed using the intercorrelation of the PVs, that is, the mean of the lower diagonal of the correlation matrix for the five PVs for each factor estimated. Hereafter, PVs are referred to as latent factor scores for simplicity.

In the second step of the analysis, the concurrent validity of the final model was tested. Generalised linear models were used to examine associations between the latent factor scores derived in the first step of the analysis and children's academic performance at 8-9 years. Analyses accounted for clustering and sample weights in the LSAC data to estimate appropriate (robust) standard errors. The sociodemographic lens includes the presence of a medical condition or disability, and $n=84(1.91 \%)$ children were reported by parents as having a medical condition or disability associated with 'difficulty learning or understanding things'. To rule out the possibility that learning difficulties were simply predicting learning problems, we performed the analysis on the whole sample (with and without adjusting for learning disability) and also excluding children with learning disability, and results were similar across all approaches.

\section{RESULTS}

\section{Testing the hypothesised framework of disadvantage}

Using CFA, four different ways of structuring the data were compared (table 2). According to the combined criteria of lower PPC estimates and parsimony, the best fitting model was model 3 , structuring the data according to the four lenses of sociodemographic, geographical environments, health conditions and risk factors.

Table 3 presents the final model with standardised factor loadings. Correlations between the four factors (table 4) were relatively low indicating that they were related but unique. Scale reliability was acceptable with $\alpha$ estimates in range $0.63-0.84$.

Table 3 Factor loadings for optimal model reflecting the four factors of sociodemographic, geographical environments, health conditions and risk factors

\begin{tabular}{|c|c|c|c|c|}
\hline & \multicolumn{4}{|l|}{ Factor loadings } \\
\hline & Sociodemographic & Geographical environments & Health conditions & Risk factors \\
\hline Child speaks language other than English & 0.26 & - & - & - \\
\hline Child has medical condition or disability & 0.11 & - & - & - \\
\hline Main caregiver income & 0.53 & - & - & - \\
\hline Household income & 0.77 & - & - & - \\
\hline Main caregiver speaks language other than English & 0.16 & - & - & - \\
\hline Main caregiver level of education & 0.43 & - & - & - \\
\hline Main caregiver occupation & 0.56 & - & - & - \\
\hline Main caregiver financial hardship & 0.55 & - & - & - \\
\hline Parents of child are partners & 0.62 & - & - & - \\
\hline Number of people in household & 0.14 & - & - & - \\
\hline Neighbourhood liveability & - & 0.34 & - & - \\
\hline Community socioeconomic status & - & 0.94 & - & - \\
\hline Urban versus regional location & - & 0.63 & - & - \\
\hline Child tooth decay & - & - & 0.25 & - \\
\hline Main caregiver depression & - & - & 0.87 & - \\
\hline Main caregiver medical condition or disability & - & - & 0.31 & - \\
\hline Child body mass index & - & - & - & 0.14 \\
\hline Main caregiver body mass index & - & - & - & 0.19 \\
\hline Child eats high fat foods and high sugar drinks & - & - & - & 0.16 \\
\hline Main caregiver smoking status & - & - & - & 0.30 \\
\hline Main caregiver binge drinking & - & - & - & 0.11 \\
\hline Child unmet need for services & - & - & - & 0.28 \\
\hline Main caregiver physical arguments with partner & - & - & - & 0.48 \\
\hline Home education environment & - & - & - & 0.19 \\
\hline Number of homes child lived in & - & - & - & 0.16 \\
\hline Child physical inactivity & - & - & - & 0.09 \\
\hline Main caregiver argumentative partner relationship & - & - & - & 0.54 \\
\hline Main caregiver angry parenting style & - & - & - & 0.37 \\
\hline Stressful life events within the family & - & - & - & 0.40 \\
\hline Main caregiver unmet need for social support & - & - & - & 0.64 \\
\hline
\end{tabular}


Table 4 Intercorrelations, reliability and concurrent validity of factors

\begin{tabular}{|c|c|c|c|c|}
\hline & Sociodemographic & Geographical environments & Health conditions & Risk factors \\
\hline \multicolumn{5}{|l|}{ Correlations between factors } \\
\hline Sociodemographic & 1 & & & \\
\hline Geographical environments & 0.47 & 1 & & \\
\hline Health conditions & 0.21 & 0.10 & 1 & \\
\hline Risk factors & 0.33 & 0.18 & 0.76 & 1 \\
\hline \multicolumn{5}{|l|}{ Reliability (Cronbach's $\alpha$ ) } \\
\hline & 0.75 & 0.84 & 0.71 & 0.63 \\
\hline \multicolumn{5}{|c|}{ Association with academic performance (concurrent validity) } \\
\hline$\beta(95 \% \mathrm{Cl})^{*}$ & $-66.89(-75.08$ to -58.70$)$ & $-51.70(-58.48$ to -44.91$)$ & $-27.03(-39.29$ to -14.77$)$ & $-36.85(-46.26$ to -27.43$)$ \\
\hline
\end{tabular}

$\mathrm{P}<0.05$ for all correlations and coefficients.

${ }^{*} n=84(1.91 \%)$ of children with a learning disability were excluded from this analysis.

\section{Concurrent validity of the disadvantage model}

Continuous latent factor scores for sociodemographic, geographical environments, health conditions and risk factors were derived for each participant during the CFA. Associations between these latent factor scores and academic performance at 8-9 years supported the concurrent validity of the optimal model (table 4). Each of the factors had substantial relationships with children's later academic skills, predicting poorer skills as expected.

\section{DISCUSSION}

We aimed to rigorously test our framework of child disadvantage (figure 1) at 4-5 years. The findings indicated that a four-factor model representing the social determinant lenses of sociodemographic, geographical environments, health conditions and risk factors was a superior fit for the data compared with alternative models. The model also showed good concurrent validity, with all four factors predicting children's academic performance 3-4 years later. This theoretically informed and empirically tested framework of child disadvantage is well equipped to inform the extent of child health and development inequities and opportunities to intervene.

This study has successfully applied the previously published model proposed by Koh et $a^{22}$ of four 'lenses' for viewing the social determinants of health to a child population. The results suggest that it is an empirically valid structure for representing childhood disadvantage. Consistent with current thinking, ${ }^{119}$ child disadvantage was best measured as a multidimensional construct: the low-moderate intercorrelations between the lenses provide evidence that they represent distinct but related aspects of disadvantage in a child population. Although the model structured according to children's bioecological contexts was not the statistically preferred model, a range of child-level, family-level and community-level indicators loaded meaningfully on each of the lenses. This reinforces the importance of considering children's bioecological contexts when conceptualising and measuring disadvantage. $^{21}$

Compared with traditional socioeconomic indicators, this framework of child disadvantage seems to more adequately capture the 'real-life' experiences of children and the varied influences on their development. There are a number of measures of child poverty that similarly also extend beyond socioeconomic indicators (eg, the UK Poverty and Social Exclusion Survey ${ }^{34}$ ); however, these measures have been mostly designed to identify and describe the most deprived children. By including variables that ranged across the full disadvantage continuum (from most to least disadvantaged), our approach is well suited to exploring how incremental increases in disadvantage on each lens may be associated with shifts in children's outcomes.

Each of the four lenses showed evidence of concurrent validity. Specifically, each was associated with academic performance at 8-9 years. The well-established association ${ }^{35}$ between disadvantage and academic performance is likely due to a range of mechanisms, such as less access to resources that promote learning in the home ${ }^{36}$ or to quality early childhood programmes and schools. ${ }^{37}$ It may also be due to shared causes like heritability of conditions impacting on both family disadvantage and children's school experience. We explored the association with academic performance as a validity check to ensure the model was operating sensibly in relation to a known correlate of disadvantage, but it is worthy of focused exploration in future work.

\section{Strengths and limitations}

The breadth and richness of data available within the LSAC allowed us to rigorously test our framework. Nevertheless, some aspects could not be measured due to a lack of available data. Within the LSAC, there will be opportunities to capture more aspects of this framework in the future through data linkage, including features of the built environment (eg, neighbourhood walkability) which are important aspects of the geographical environments lens. ${ }^{38}$ To further extend on this work, it will be valuable for future research to replicate the current findings in different cohorts, with different sets of indicators available across the lenses, and validated against different outcomes of interest (eg, employment).

This framework will also need to be tested in populations outside of Australia. The social determinants of health are often context dependent, and differ across countries. ${ }^{4}$ The four factors contributing to childhood disadvantage in Australia, and the indicators used to measure them, may or may not be relevant to all countries. International researchers should consider this possibility when applying this framework to their specific population of interest. ${ }^{39}$

In operationalising Koh et al's ${ }^{22}$ theoretical model of four social determinants lenses, we needed to consider how to treat the small number of indicators that could conceivably sit in more than one lens. Given that Koh et al ${ }^{22}$ did not define what indicators should sit under each lens, we categorised such indicators based on what we deemed most closely resembled the original theoretical model. Researchers applying this framework may choose to categorise such ambiguous indicators differently, as is most relevant to their context and aims.

We included the full variation of continuous indicators (eg, from optimal parenting to less effective parenting behaviours), 
but many indicators were geared towards disadvantage (eg, caregivers unmet need for social support). There remain opportunities to further develop the advantage end of such scales to incorporate and measure the full spectrum of experiences from disadvantage to advantage.

\section{Implications and future directions}

Given the ubiquity of child inequities, ${ }^{412}$ and continuing discussion about how adversity impacts development, ${ }^{40}$ our framework is likely to be of international interest. The indicators used to populate this framework are commonly collected within population-based cohorts, such as the Millennium Cohort Study (UK) and the Early Childhood Longitudinal Study (USA). Although it is unlikely that all aspects of figure 1 will be perfectly captured in any one study (as was the case here), this framework can guide researchers to better use the data available to them and be more explicit about the data not captured.

As Braveman et $a l^{39}$ have noted, a 'one size fits all' approach to measuring disadvantage can be problematic, and thoughtful consideration is needed in applying this framework depending on the specific research question being explored. Care should be taken in ensuring separation between exposure and outcome. For example, exploring the impact of child disadvantage on obesity would require parsing out child-level disadvantage indicators such as body mass index (risk factors lens). Having an explicit empirically validated framework to support this decision making is highly valuable.

Given that disadvantage can change over time, ${ }^{41}$ future work could examine trajectories of disadvantage over childhood using this framework, more comprehensively documenting the nature of disadvantage experienced during other key developmental periods such as adolescence. Another critical area for further exploration is the interaction and contribution of the lenses to children's outcomes across developmental domains (eg, cognitive, social-emotional, physical health). The capacity to capture this interplay is one of the key benefits of applying this more comprehensive framework to future child health and development studies. It will also allow explicit testing of how the current approach compares with narrower socioeconomic measures in explaining children's developmental outcomes; we hypothesise

\section{What is already known on this subject}

Child development occurs within a complex transactional system where biology interacts with the environment in which children live, learn and grow (social determinants). Measurement of the continuum of child disadvantage based on socioeconomic status alone may substantially underestimate the extent, experience and modifiability of disadvantage in childhood.

\section{What this study adds}

This study provides a tested comprehensive framework for understanding and operationalising the continuum of child disadvantage, informed by social determinants and bioecological models of child development. This framework can be used to generate measures that more accurately quantify the extent of child health and developmental inequities and elucidate policysensitive intervention pathways. that narrower measures would underestimate the extent of this effect.

With a comprehensive framework of disadvantage, we can identify those policies and interventions capable of attenuating the relationship between disadvantage and children's outcomes. The four lenses of sociodemographic, geographical environments, health conditions and risk factors, which manifest at the child, family and community levels, offer a useful and pragmatic framework for policy-makers to consider social determinants as potentially modifiable opportunities to addressing inequities. ${ }^{22}$

\section{CONCLUSIONS}

Child health and developmental inequities are a major public health issue. ${ }^{2411}$ Finding new evidence-based ways to improve outcomes for disadvantaged children can generate significant social and economic benefits through savings in health, education and welfare budgets, and improved productivity. ${ }^{42}$ Understanding and (importantly) addressing inequities will be facilitated by robust conceptualisation and measurement of disadvantage. This study has generated a framework and approach that can capture the complexity of children's experiences across the multiple environments in which their development unfolds.

\section{Author affiliations \\ ${ }^{1}$ Centre for Community Child Health, Murdoch Children's Research Institute, Royal Children's Hospital, Melbourne, Victoria, Australia \\ ${ }^{2}$ Department of Paediatrics, University of Melbourne, Melbourne, Victoria, Australia ${ }^{3}$ Centre for Education Policy and Practice, Australian Council for Educational Research, Melbourne, Victoria, Australia \\ ${ }^{4}$ College of Business, Government and Law, Flinders University, Adelaide, South Australia, Australia \\ ${ }^{5}$ Centre for Urban Research, RMIT University, Melbourne, Victoria, Australia ${ }^{6}$ Developmental Medicine, The Royal Children's Hospital, Parkville, Victoria, Australia ${ }^{7}$ Department of Clinical Sciences, Murdoch Children's Research Institute, Melbourne, Victoria, Australia \\ ${ }^{8}$ Clinical Epidemiology and Biostatistics Unit, Murdoch Children's Research Institute, Melbourne, Victoria, Australia \\ ${ }^{9}$ Department of Community Child Health, Sydney Children's Hospital Network, Sydney, New South Wales, Australia \\ ${ }^{10}$ Department of Medicine, University of New South Wales, Sydney, New South Wales, Australia \\ ${ }^{11}$ Research and Policy Centre, Brotherhood of Saint Laurence, Melbourne, Victoria, Australia}

Acknowledgements The authors wish to acknowledge the support of the Changing Children's Chances investigator team. We also thank Emeritus Professor Nick Spencer for feedback on an earlier version of this manuscript, and Elodie O'Connor and Shiau Chong for assistance in manuscript preparation. This paper uses unit record data from Growing Up in Australia, the Longitudinal Study of Australian Children. The study is conducted in partnership between the Department of Social Services (DSS), the Australian Institute of Family Studies (AIFS) and the Australian Bureau of Statistics (ABS). The findings and views reported in this paper are those of the authors and should not be attributed to DSS, AIFS or the ABS.

Contributors SG contributed to and oversaw the planning and reporting of the work described in this article. $M O^{\prime} C, D C$ and SG contributed to the planning, conduct and reporting of the work described in this article and wrote the first draft of the manuscript. DC conducted the data analysis. GR, HB, KW, FM, SW, AK and ATK contributed to the planning and reporting of the work described in this article.

Funding This research is funded by Australian Research Council Discovery Grant DP160101735, and is supported by the Victorian Government's Operational Infrastructure Support Program. SG is supported by Australian National Health and Medical Research Council (NHMRC) Career Development Fellowship 1082922, and FM is supported by NHMRC Career Development Fellowship 1111160.

Competing interests None declared.

Ethics approval The LSAC methodology was approved by the Australian Institute of Family Studies Human Research Ethics Review Board.

Provenance and peer review Not commissioned; externally peer reviewed. 
(c) Article author(s) (or their employer(s) unless otherwise stated in the text of the article) 2018. All rights reserved. No commercial use is permitted unless otherwise expressly granted.

\section{REFERENCES}

1 Sen A. Development as freedom. Oxford: Oxford University Press, 2001.

2 Braveman P. Health disparities and health equity: concepts and measurement. Annu Rev Public Health 2006;27:167-94.

3 Minujin A, Delamonica E, Davidziuk A, et al. The definition of child poverty: a discussion of concepts and measurements. Environ Urban 2006;18:481-500.

4 Commission on Social Determinants of Health. Closing the gap in a generation: health equity through action on the social determinants of health. Final report of the commission on social determinants of health. Geneva: World Health Organisation, 2008

5 Spencer N. Social, economic, and political determinants of child health. Pediatrics 2003;112:704-6.

6 Victorino CC, Gauthier AH. The social determinants of child health: variations across health outcomes - a population-based cross-sectional analysis. BMC Pediatr 2009;9:53.

7 Starfield B, Robertson J, Riley AW. Social class gradients and health in childhood. Ambul Pediatr 2002;2:238-46.

8 Adler NE, Boyce T, Chesney MA, et al. Socioeconomic status and health. The challenge of the gradient. Am Psychol 1994;49:15-24.

9 Nicholson JM, Lucas N, Berthelsen D, et al. Socioeconomic inequality profiles in physical and developmental health from 0-7 years: Australian National Study. J Epidemiol Community Health 2012;66:81-7.

10 Brooks-Gunn J, Duncan G, Britto P. Are socio-economic gradients for children similar to those for adults? Achievement and health of children in the United States. In: Keating D, Hertzman C, eds. Developmental health and the wealth of nations: social, biological and educational dynamics. New York: Guilford Press, 1999.

11 Braveman P, Gruskin S. Defining equity in health. J Epidemiol Community Health 2003;57:254-8.

12 UNICEF Innocenti Research Centre. Measuring child poverty: new league tables of child poverty in the world's rich countries. Innocenti Report Card 10. Florence: UNICEF Innocenti Research Centre, 2012.

13 Hertzman C. Framework for the social determinants of early child development. Encyclopedia on early childhood development. Canada: University of British Columbia, 2010.

14 Marmot M, Friel S, Bell R, et al. Closing the gap in a generation: health equity through action on the social determinants of health. The Lancet 2008;372:1661-9.

15 Goldfeld SR, Oberklaid F. Maintaining an agenda for children: the role of data in linking policy, politics and outcomes. Med J Aust 2005;183:209-11.

16 Neckerman KM, Garfinkel I, Teitler JO, et al. Beyond income poverty: measuring disadvantage in terms of material hardship and health. Acad Pediatr 2016;16:S52-9.

17 Blackburn CM, Spencer NJ, Read JM. Prevalence of childhood disability and the characteristics and circumstances of disabled children in the UK: secondary analysis of the family resources survey. BMC Pediatr 2010;10:21.

18 Roelen K, Gassmann F, de Neubourg C. False positives or hidden dimensions: what can monetary and multidimensional measurement tell us about child poverty in Vietnam? Int J Soc Welf 2012;21:393-407.
19 Wolff J, de-Shalit A. Disadvantage. Oxford: Oxford University Press, 2007.

20 Bronfenbrenner U. Making human beings human: Bioecological perspectives on human development. USA: Sage Publications, Inc, 2004.

21 Maggi S, Irwin LJ, Siddiqi A, et al. The social determinants of early child development: an overview. J Paediatr Child Health 2010;46:627-35.

22 Koh HK, Oppenheimer SC, Massin-Short SB, et al. Translating research evidence into practice to reduce health disparities: a social determinants approach. Am J Public Health 2010:100:572-80.

23 Sabol TJ, Pianta RC. Patterns of school readiness forecast achievement and socioemotional development at the end of elementary school. Child Dev 2012:83:282-99.

24 Soloff C, Lawrence D, Misson S, et al. LSAC Technical paper No. 3. Wave 1 weighting and non-response. Melbourne, Australia: Australian Institute of Family Studies, 2006.

25 Soloff C, Lawrence D, Johnstone R. LSAC Technical paper No. 1. Sample design. Melbourne, Australia: Australian Institute of Family Studies, 2005.

26 Duncan G, Gibson C. Selection and attrition in the NICHD childcare study's analyses of the impacts of childcare quality on child outcomes. Evanston, IL: Northwestern University, 2000.

27 Daraganova G, Edwards B, Sipthorp M. Using National Assessment Program - Literacy and Numeracy (NAPLAN) data in the Longitudinal Study of Australian Children (LSAC). Melbourne, Australia: Australian Institute of Family Studies, 2013.

28 Australian Institute of Family Studies. Using LSAC data. Melbourne, Australia: Australian Institute of Family Studies.

29 Australian Institute of Family Studies. Wave 1-3 rationale document. Melbourne, Australia: Australian Institute of Family Studies, 2016.

30 Muthén B, Asparouhov T. Bayesian structural equation modeling: a more flexible representation of substantive theory. Psychol Methods 2012;17:313-35.

31 Fabrigar LR, Wegener DT, MacCallum RC, et al. Evaluating the use of exploratory factor analysis in psychological research. Psychol Methods 1999;4:272-99.

32 Von Davier M, Gonzalez E, Mislevy R. What are plausible values and why are they useful? IERI monograph series 2009;2:9-36.

33 Rubin DB. Multiple imputation for nonresponse in surveys. John Wiley \& Sons, 2004

34 Gordon D, Adelman L, Ashworth K, et al. Poverty and social exclusion in Britain. York: Joseph Rowntree Foundation, 2000.

35 Hair NL, Hanson JL, Wolfe BL, et al. Association of child poverty, brain development, and academic achievement. JAMA Pediatr 2015;169:822-9.

36 Bradley RH, Corwyn RF. Socioeconomic status and child development. Annu Rev Psychol 2002;53:371-99.

37 Cloney D, Cleveland G, Hattie J, et al. Variations in the availability and quality of early childhood education and care by socioeconomic status of neighborhoods. Early Educ Dev 2016;27:384-401.

38 Villanueva K, Badland H, Giles-Corti B, et al. Using spatial analysis of the Australian early development index to advance our understanding of 'neighbourhood effects' research on child health and development. J Paediatr Child Health 2015;51:577-9.

39 Braveman PA, Cubbin C, Egerter $\mathrm{S}$, et al. Socioeconomic status in health research: one size does not fit all. JAMA 2005:294:2879-88.

40 Evans GW. Childhood poverty and adult psychological well-being. Proc Natl Acad Sci USA 2016:113:14949-52.

41 Graham H, Power C. Childhood disadvantage and adult health: a lifecourse framework. London: Health Development Agency, 2004.

42 Woolfenden S, Goldfeld S, Raman S, et al. Inequity in child health: the importance of early childhood development. J Paediatr Child Health 2013;49:E365-9. 